\title{
Remediation of coastal sandy soils polluted by petroleum leaks
}

\author{
J. Tomás Albergaria ${ }^{1}$, C. Delerue-Matos ${ }^{1}$ \\ \& M. da Conceição M. Alvim-Ferraz ${ }^{2}$ \\ ${ }^{I}$ REQUIMTE, Instituto Superior de Engenharia do Porto, Portugal \\ ${ }^{2}$ LEPAE, Departamento de Engenharia Química, Faculdade de \\ Engenharia, Universidade do Porto, Portugal
}

\begin{abstract}
The group of pollutants containing benzene, toluene, ethylbenzene and xylene (commonly known as BTEX) is typically related to petroleum leaks. According to the United States Environmental Protection Agency that group of pollutants is one of the most often found in contaminated soils. The remediation technology that is commonly applied to the remediation of soils contaminated with those pollutants is Soil Vapour Extraction (SVE); through the induction of vacuum to the soil matrix, SVE promotes the circulation of air within the soil, conducting the contaminant vapours removed to extraction wells and later to the atmosphere, after convenient treatment.

The location of petroleum refineries strongly depends on the requirement of significant amounts of water for process, cooling and steam; besides of that, mainly due to the need of guarantying efficient supply of raw materials and shipping of products, petroleum refineries are usually located in coastal areas, commonly constituted by sandy soils; coastal sandy soils normally have low content of natural organic matter, but high soil water content (SWC) that has an important role on the distribution of the pollutants in the soil phases and, consequently, on the time and efficiency of remediation with SVE. The complete knowledge of that role is extremely necessary to adopt the most efficient strategy for the site remediation, aiming, namely, to preview the remediation time required to reach a defined remediation efficiency imposed by legislation.

This work presents the study of the influence of SWC on the remediation of soils contaminated with benzene and xylene using SVE. The main objectives
\end{abstract}


were to evaluate the impact of SWC: i) on the contaminant distribution in the soil, ii) on the remediation time, and iii) on the process efficiency.

Keywords: petroleum leaks, soil remediation, sandy soils, soil vapour extraction, soil water content.

\section{Introduction}

The petroleum refineries are strategically located in coastal areas due their needs of extremely high amounts of cold water and to easily and rapidly receive raw materials and deploy products. Coastal areas are normally and basically constituted by sandy soils that present specific and well known characteristics. Albergaria et al. [1] concluded that the adsorption capacity of sandy soils is extremely low and that the contaminants are mostly located in the gas phase of the soil, indicating that they have high mobility; this allows the horizontal and vertical spreading of contaminants, creating the possibility of risk for public health.

Aiming the protection of the environment and the public health, several soil remediation technologies have been used in the last decades [2]. Among them, Soil Vapour Extraction (SVE) can be highlighted, due to be a well known technology of relatively easy application and also due to its high efficiency. This technology can be applied to contamination located in the unsaturated zone of the soil and involves the application of vacuum to the contaminated zone of the soil creating an airflow within the soil matrix. This airflow will transport the volatile contaminants to extraction wells that will remove the contaminant from the soil to air treatment units that ensure that the contaminants are not transferred to the atmosphere $[3,4]$.

SVE efficiency depends on the contaminant mass transfer phenomena that occur in the soil, from the different soil phases (solid, aqueous and non-aqueous liquid) to the gas phase. These transfers are affected by several parameters such as vapour pressure and water solubility of the contaminants and contents of organic matter and water of the soil.

The group of pollutants containing benzene, toluene, ethylbenzene and xylene (commonly known as BTEX) is typically related to petroleum leaks. According to the United States Environmental Protection Agency that group of pollutants is one of the most often found at contaminated soils; the remediation technology that is commonly applied to the remediation of soils contaminated with those pollutants is Soil Vapour Extraction (SVE).

Soil water content (SWC) acts as a receiver of the contaminant through dissolution, reduces the air-filled porosity of the soil and can act as a barrier between the pollutant and the soil matrix, hindering the adsorption of contaminants on the solid phase of the soil; when the water content is high the pores are almost filled creating difficulties to the air movement and consequently the extraction of the contaminant from the soil [1]. However, water of the soil can compete with the contaminant for the adsorption sites creating desorption of the contaminant, allowing it to be transported by the airflow to the exterior of the soil [5]. 
The knowledge of the contaminant behavior in soils with different soil water contents is of extreme interest because it can supply information for the selection of the most efficient strategy for the site remediation, aiming, namely, to preview the remediation time required to reach a defined remediation efficiency imposed by legislation.

This work presents the study of the influence of SWC on the remediation of soils contaminated with benzene and xylene using SVE. The main objectives were to evaluate the impact of SWC: i) on the contaminant distribution in the soil, ii) on the remediation time, and iii) on the process efficiency.

\section{Experimental}

\subsection{Reagents}

Benzene and xylene were obtained, respectively, from Riedel-de Haën and from Merck. All substances were of analytical grade quality.

\subsection{Apparatus}

An Ai Cambridge GC95 chromatograph equipped with a Chrompack Hayesep Q 80-100 mesh $(3 \mathrm{~m} \times 1 / 4 " \times 4 \mathrm{~mm})$ column and a flame ionisation detector (FID) were used for the quantification of the contaminant in the gas emissions. The injector and the detector were set at $230^{\circ} \mathrm{C}$ and the oven was maintained at $200^{\circ} \mathrm{C}$. Flame gases were: air at $270 \mathrm{~cm}^{3} \mathrm{~min}^{-1}$ (STP), and hydrogen at $30 \mathrm{~cm}^{3}$ $\min ^{-1}$ (STP). The carrier gas was nitrogen at $30 \mathrm{~cm}^{3} \min ^{-1}$ (STP). Chromatographic data were recorded using a Barspec Data System software (Barspec System, Inc, Israel). The external standard calibration method was used. Under the above described experimental conditions, the retention times of the contaminants were: 25 minutes for benzene and 101 minutes for xylene.

\subsection{Gas chromatographic analysis}

The quantification of benzene and xylene were performed by Gas Chromatography using the external standard calibration method. For each contaminant, seven standards were prepared and analysed in triplicate within the desired range ( 0.7 to $53 \mathrm{~g} \mathrm{~m}^{-3}$ for benzene and 0.7 to $17 \mathrm{~g} \mathrm{~m}^{-3}$ for xylene). The obtained calibration curves showed correlation coefficients between 0.9944 and 0.9996 . The relative deviations of the results of the triplicate analysis were below $4.1 \%$ which indicates that the method has an adequate precision.

\subsection{Soil preparation and characterization}

The used sandy soil was collected at $2 \mathrm{~m}$ depth in a beach near Porto (Portugal). This soil was mainly constituted of silica and shell debris. The soil was stored in appropriate vessels to ensure that no changes occurred to its physicochemical properties. The work here described was performed using prepared soils; the behaviour of real soils will be compared in a different publication. The 
preparation of the soils with different water contents involved five steps: a) washing until clear water was obtained; b) drying, first at room temperature during 5 days and then at $110^{\circ} \mathrm{C}$ for 24 hours; c) sieving through a $2 \mathrm{~mm}$ sieve to obtain a granulometric fraction of the soil with uniform physical properties; d) adding different amounts of water to the sand in order to induce 2 and 4\% water contents; and e) homogenising. The prepared soils were stored in stoppered vessels and identified as $\mathrm{P}_{0}, \mathrm{P}_{2}$ and $\mathrm{P}_{4}$, the subscript indicating the water content $(\%)$. International standard methodologies were used for the soil characterization that included the determination of apparent density, particle density, porosity, $\mathrm{pH}$, and the contents of water and natural organic matter [6].

\subsection{Soil vapour extraction experiments}

The soil columns for SVE experiments were prepared in four steps: a) introduction of the soil into the column; b) contamination by adding $1.00 \mathrm{~g}$ of contaminant in the top of the column allowing the percolation; c) equilibrium settling. After the equilibrium was reached the vacuum pump was turned on and the airflow rates were adjusted using a rotameter. The air passed through the column, percolating through the soil inside the column, and then through a sampling system where the contaminated emissions were collected and afterwards monitored by gas chromatography. To control atmospheric contamination, the contaminants in the emissions were adsorbed on activated carbon before reaching the atmosphere. The remediation process was considered finished when the concentration of the contaminant in the gas phase of the emission leaving the soil column was below $1.0 \mathrm{mg} \mathrm{L}^{-1}$. The time required to reach this point was considered the remediation time.

In the end of SVE the process efficiency was calculated using equilibrium isotherms that relate the concentration of the contaminant in the gas phase with the mass of contaminant in the soil matrix. This tool was used to calculate the amount of contaminant remaining in the soil matrix after the SVE. Equilibrium isotherms were obtained using soil columns similar to those previously described, but using different amounts of contaminant $(0.05$ to $0.400 \mathrm{~g})$. When the equilibrium was reached the concentration of the contaminant in the gas phase was calculated and related with the level of contamination of the soil.

\section{Results}

\subsection{Soil characteristics}

Table 1 shows the results of soil characterisation. In all cases the natural organic matter content was below the limit of detection $(0.02 \%)$ and the clay content was negligible; the relatively high $\mathrm{pH}$ values can be explained by the presence of shell debris. 
Table 1: $\quad$ Characteristics of $\mathrm{P}_{0}, \mathrm{P}_{2}$ and $\mathrm{P}_{4}$ soils (particle size $<2 \mathrm{~mm}$ ).

\begin{tabular}{|c|c|c|c|c|c|c|}
\hline Soil & $\mathrm{pH}$ & $\begin{array}{c}\text { Apparent density } \\
\left(\mathrm{g} \mathrm{mL}^{-1}\right)\end{array}$ & $\begin{array}{c}\text { Particle density } \\
\left(\mathrm{g} \mathrm{mL}^{-1}\right)\end{array}$ & $\begin{array}{c}\text { Porosity } \\
(\%)\end{array}$ & $\begin{array}{c}\text { Water content } \\
(\%)\end{array}$ & $\begin{array}{c}\text { Natural organic } \\
\text { matter content (\%) }\end{array}$ \\
\hline $\mathrm{P}_{0}$ & 8.8 & 1.5 & 2.5 & 42 & 0.0 & $<0.02$ \\
\hline $\mathrm{P}_{2}$ & 8.8 & 1.3 & 2.5 & 49 & 2.0 & $<0.02$ \\
\hline $\mathrm{P}_{4}$ & 8.8 & 1.2 & 2.5 & 51 & 4.0 & $<0.02$ \\
\hline
\end{tabular}

\subsection{Contaminant distribution in soil}

The elaboration of the equilibrium isotherms allowed to calculate the amounts of contaminant in all the soil phases (gaseous, aqueous, non-aqueous liquid and solid) (Albergaria et al. [1]). Figure 1 shows how the contaminants distributed among these phases in the three prepared soils studied, for three levels of contamination $\left(12,50\right.$ and $\left.100 \mathrm{mg} \mathrm{kg}^{-1}\right)$.

Figure 1 shows that increasing the soil water content increased the percentage of contaminant in the gas and aqueous phases and decreased the percentage of contaminant in the solid and non-aqueous liquid phases (the water covering the soil particles hindered the bonding between the contaminant and the solid phase). The percentage of contaminant in the aqueous phase is low because of the low water solubility of both contaminants, lower for xylene.
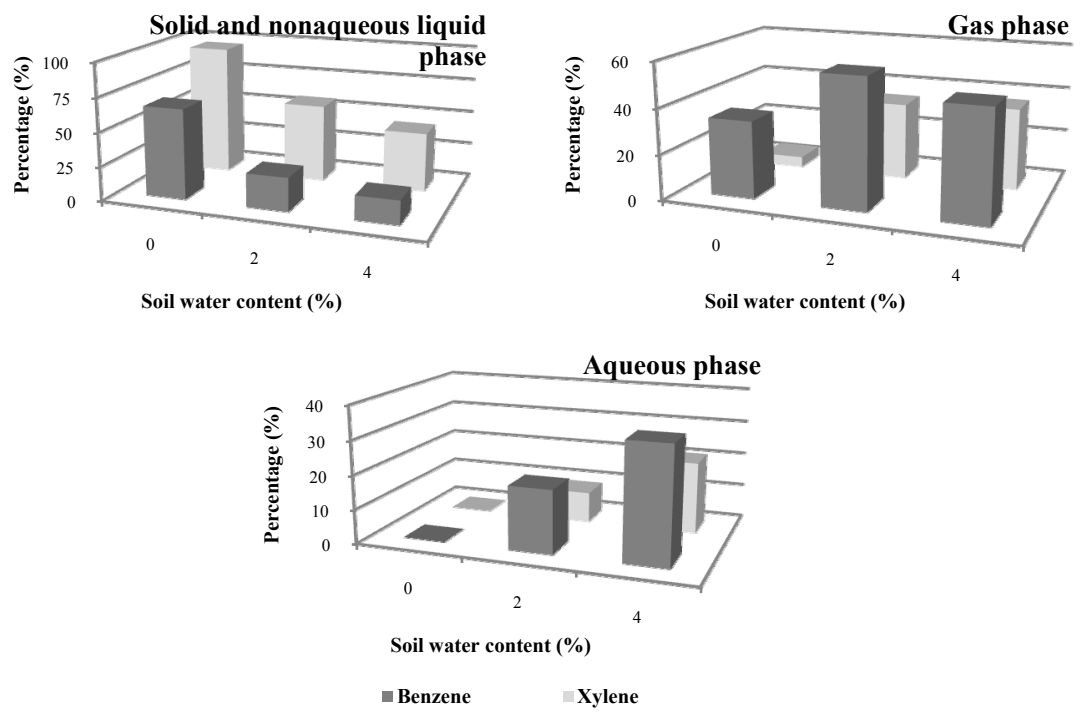

Figure 1: Distribution of the contaminants among the soil phases. 


\subsection{Soil vapour extraction}

The influence of water content on SVE was also evaluated considering the remediation time and process efficiency.

Figure 2 presents the remediation times for all the experiments, showing that SWC has a slight but negative impact on SVE turning the remediation process more time consuming. This could be explained by the fact the higher SWC implies lower soil porosities and higher difficulty for contaminant percolation through the soil matrix.

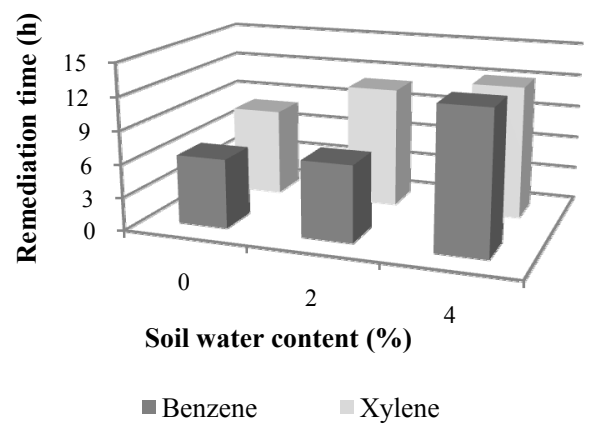

Figure 2: SVE remediation times for $\mathrm{P}_{0}, \mathrm{P}_{2}$ and $\mathrm{P}_{4}$ soils contaminated separately with benzene and xylene (airflow rate $=5.0 \mathrm{~L} \mathrm{~h}^{-1}$ ).

Figure 3 presents the influence of SWC on the remediation efficiencies, showing that SWC has no significant impact on the process efficiency (all efficiencies were above 93\%). This could be explained by the fact that the sandy soils have low capacity to adsorb the contaminants leaving them extremely mobile and easy to extract.

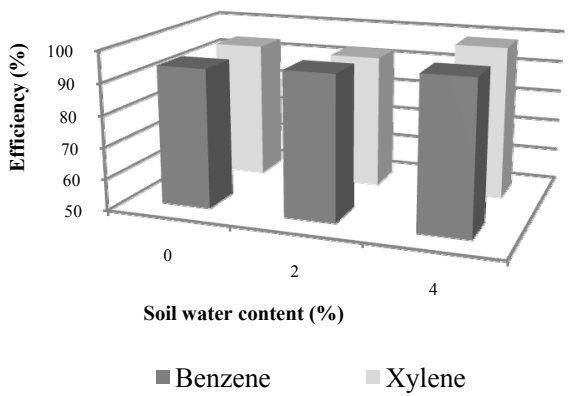

Figure 3: $\quad$ SVE remediation efficiencies for $\mathrm{P}_{0}, \mathrm{P}_{2}$ and $\mathrm{P}_{4}$ soils contaminated separately with benzene and xylene (airflow rate $=5.0 \mathrm{~L} \mathrm{~h}^{-1}$ ). 


\section{Conclusions}

For sandy soils with negligible amounts of clay and natural organic matter, contaminated separately with benzene and xylene and remediated using SVE it was concluded that:

a) all the remediation experiments had efficiencies above $93 \%$;

b) increasing of soil water content led to: i) an increase of the contaminant percentage in the gas and aqueous phases and a decrease of contaminant percentage in the solid and non-aqueous liquid phases;

c) soil water content had a slight but negative impact on SVE turning the remediation processes more time consuming;

d) soil water content had no significant impact on the process efficiency.

\section{Acknowledgement}

The authors are grateful to Fundação para a Ciência e Tecnologia (Projecto $\mathrm{PTDC} / \mathrm{ECM} / 68056 / 2006$ ) for the material support for this work.

\section{References}

[1] Albergaria, J.T., Alvim-Ferraz, M.C.M., Delerue-Matos, M. C. F., Estimation of pollutant partition in sandy soils with different water contents. Environmental Monitoring and Assessment, 171, 171-180, 2010.

[2] United STATES Environmental Protection Agency, Superfund Remedy Report (Thirteenth Edition), 2010, Retrieved March 5 th $^{\text {th }} 2011$ from http://www.epa.gov/tio/download/remed/asr/13/srr_13th_maindocument.pdf

[3] S.S. Suthersan, Soil Vapour Extraction. In: Remediation Engineering: Design Concepts. Boca Raton: Lewis Publisher Inc., pp. 27-88, 1999.

[4] Anonymous, Offgas Treatment Technologies for Soil Vapor Extraction Systems, Hazardous Waste Consultant, 24, 1.11-1.15, 2006.

[5] Tekrony, M.C., Ahlert, R.C. Adsorption of chlorinated hydrocarbon vapours onto soil in presence of water. Journal of Hazardous Materials. 84, 135-146, 2001.

[6] Albergaria, J.T., 2010. Previsão do tempo de remediação de solos contaminados usando a extracção de vapor. PhD Thesis. Faculdade de Engenharia da Universidade do Porto, Porto. 